
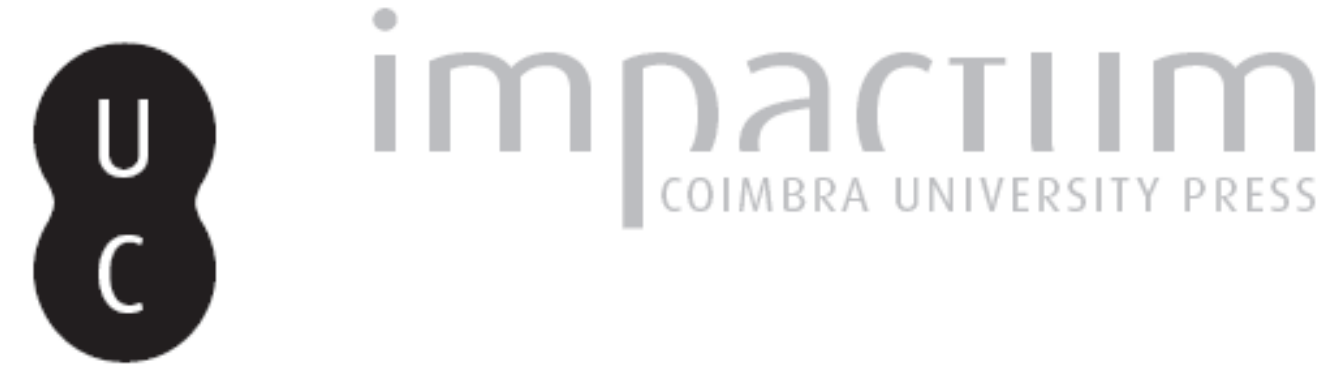

\title{
Bases legais e institucionais de planos diretores municipais: exemplos no Triângulo Mineiro, Minas Gerais, Brasil
}
Autor(es):
Mauro, Cláudio Antonio Di
Publicado por: Imprensa da Universidade de Coimbra
URL
persistente:
URI:http://hdl.handle.net/10316.2/43408
DOI:
DOI:https://doi.org/10.14195/0871-1623_36_4

Accessed : $\quad$ 26-Apr-2023 07:29:26

A navegação consulta e descarregamento dos títulos inseridos nas Bibliotecas Digitais UC Digitalis, UC Pombalina e UC Impactum, pressupõem a aceitação plena e sem reservas dos Termos e Condições de Uso destas Bibliotecas Digitais, disponíveis em https://digitalis.uc.pt/pt-pt/termos.

Conforme exposto nos referidos Termos e Condições de Uso, o descarregamento de títulos de acesso restrito requer uma licença válida de autorização devendo o utilizador aceder ao(s) documento(s) a partir de um endereço de IP da instituição detentora da supramencionada licença.

Ao utilizador é apenas permitido o descarregamento para uso pessoal, pelo que o emprego do(s) título(s) descarregado(s) para outro fim, designadamente comercial, carece de autorização do respetivo autor ou editor da obra.

Na medida em que todas as obras da UC Digitalis se encontram protegidas pelo Código do Direito de Autor e Direitos Conexos e demais legislação aplicável, toda a cópia, parcial ou total, deste documento, nos casos em que é legalmente admitida, deverá conter ou fazer-se acompanhar por este aviso.

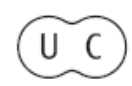




\section{Cadernos de Ceografia}

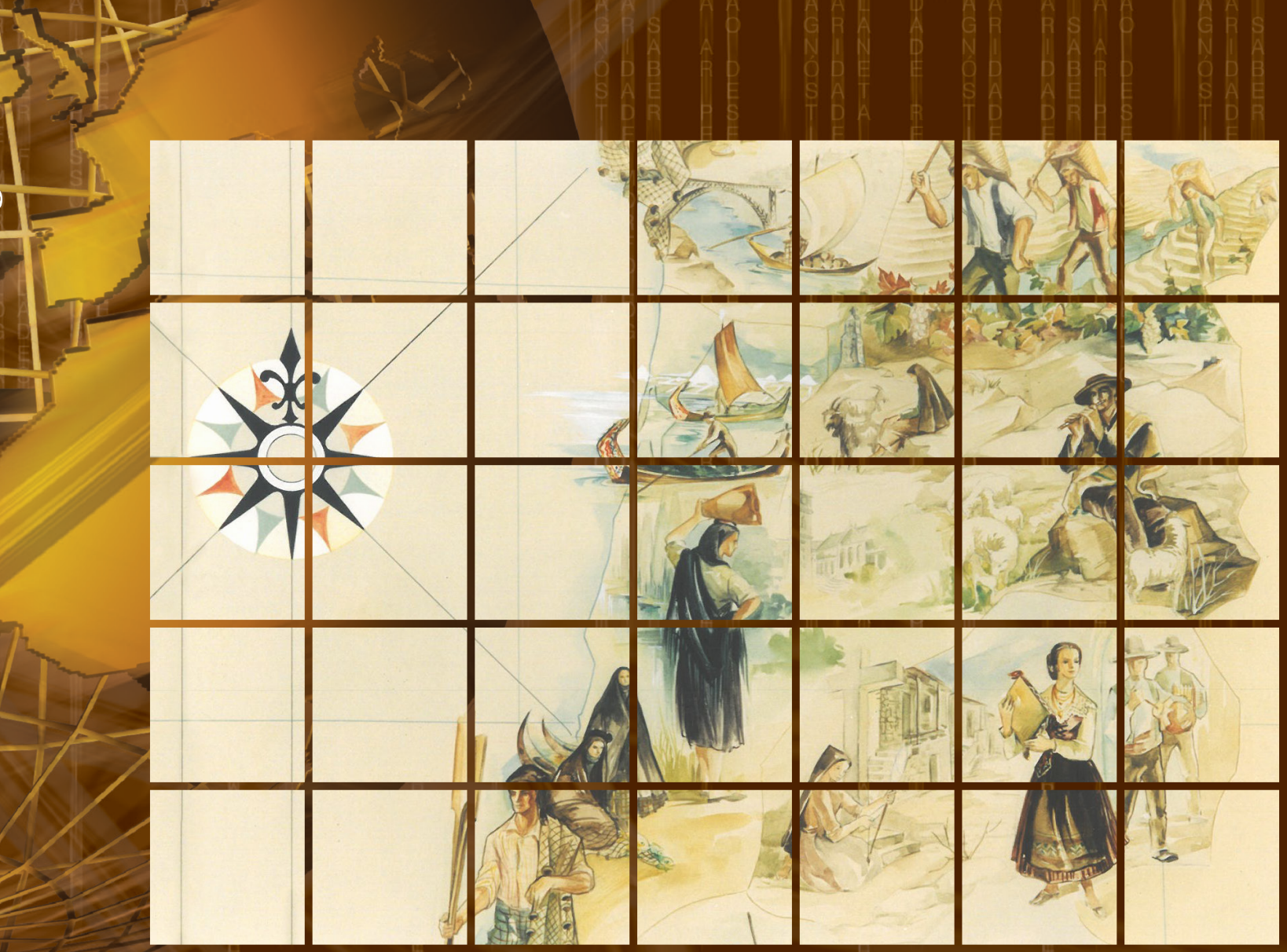

Imprensa da Universidade de Coimbra Faculdade de Letras | Universidade de Coimbra 


\section{Bases legais e institucionais de planos diretores municipais: exemplos no Triângulo Mineiro, Minas Gerais, Brasil Legal and institutional bases in municipal master plans: examples in the Triângulo Mineiro, Minas Gerais, Brazil}

\section{Cláudio Antonio Di Mauro}

Instituto de Geografia da Universidade Federal de Uberlândia claudiodimauro@ufu.br ORCID: 0000-0002-7130-4701

\section{Gláucia Carvalho Gomes}

Instituto de Geografia da Universidade Federal de Uberlândia glauciagcg@ig.ufu.br ORCID: 0000-0001-7529-2309

\section{Resumo}

As questões urbanas, consideradas em sua complexidade, não se constituem em prioridades para as políticas governamentais brasileiras. Ou são consideradas apenas em função de determinados aspectos que, em ampla medida, não se orientam pelo que está disposto no Estatuto da Cidade. Mesmo que a Constituição Federal da República Federativa do Brasil, bem como o Estatuto da Cidade sirvam de referenciais para as administrações municipais na consideração da função social da cidade e também da propriedade urbana, ainda assim as políticas aplicadas nos municípios têm se revelado deficientes. Os instrumentos contidos no Estatuto da Cidade, mesmo quando incluídos em Leis Orgânicas de Municípios que elaboram seus Planos Diretores, contudo têm suas utilizações precárias e não atendem os objetivos de garantir a cidade para todos. Os Planos Diretores de Uberlândia e Tupaciguara (MG) são exemplos de iniciativas que apontam para aproveitamento adequado das normatizações oferecidas pelo Estatuto, mas que, na prática, não foram complementadas por legislação regulamentar e encontram-se sem aplicação em suas ricas possibilidades. Mesmo com a natureza progressista de novas práticas possíveis do Estatuto da Cidade, chama muito a atenção o fato de que nos dois municípios importantes instrumentos possibilitados pelo Estatuto da Cidade, e respaldados nos respectivos Planos Diretores, não terem sido adotados de forma sistemática. IPTU progressivo, exigência do Estudo de Impacto de Vizinhança, Outorga Onerosa, Uso capião Urbano, entre outros, embora sejam práticas legalmente respaldadas, demandadas nos dois municípios, não se configuram como instrumentos efetivos para fazer cumprir a função social da propriedade em prol dos interesses sociais coletivos. Revela-se que o instituído, mesmo quando regulamentado, só é transformador em seu exercício efetivo. Explicita-se, então, a necessidade constante, sistemática e rigorosa da efetiva participação na produção da cidade. Entretanto, se o que norteia é a cidadania, e esta se compõe de deveres e direitos, reside aí um importante componente da cidade e da sociedade almejadas. E, principalmente, um avanço necessário na luta por uma cidade mais justa e democrática.

Palavras-chave: Constituição Federal; Estatuto da Cidade; Função Social da Propriedade; Cidade Democrática.

\section{Abstract}

The Urban issues, considered in their complexity, do not constitute priorities for Brazilian government policies. They are considered only in relation to certain aspects that, to a large scope, are not guided by what is laid out in the City Statute. Even though the Federal Constitution of the Brazil, as well as the City Statute provide references for municipal administrations in considering the social function of the city and the urban property, the policies applied in the municipalities have been deficient. The tools contained in the City Statute, even when included in Organic Law of Municipalities prepare their Master Plans, but have their uses precarious and do not meet the objectives of ensuring the city for everyone. The Masters Plans of Uberlândia and Tupaciguara Cities (MG/Brazil) are examples of initiatives that point to the proper use of the regulations offered by the Statute, but which in practice have not been complemented by regulatory legislation and are without application in their rich possibilities. Despite the progressive nature of possible new practices in the City Statute, it is very important to note that in the two municipalities important instruments made possible by the City Statute, and supported by the respective Master Plans, were not adopted systematically. Progressive IPTU, demand of the Neighborhood Impact Study, Onerous Granting, Urban Usucaption, among others, although they are legally supported practices, demanded in the two municipalities, are not configured as effective instruments to enforce the social function of property in the social collective interests. It's clear that the instituted, even when 
regulated, is only transformative in its effective exercise. The constant, systematic and rigorous need for effective participation in the production of the city is explained. However, if what guides is the citizenship, composed of duties and rights, we have an important component of the city and the desired society. Above all, a necessary advance in the struggle for a more just and democratic city.

Keywords: Brazil' Federal Constitution; City Statute; Social Function of Property; Democratic City.

"Estando la tierra lastimada por el poder y los triunfos de los señores de la tierra y de la guerra, el viento se alza desde lãs praderas baldias y se queja."

Eduardo Galeano (1988)

Conforme destacado na Constituição Federal do Brasil, os temas de interesses nacionais são de responsabilidade da União, aqueles de caráter regional são de responsabilidade dos Estados e do Distrito Federal e aqueles que se caracterizam como locais são de atribuição dos Municípios, todos compondo o pacto federativo. No Brasil - como federação na qual seus entes devem atuar de maneira cooperativa - não há subordinação entre eles. Assim, os entes federados devem atuar de maneira articulada, tendo como referência principal o texto constitucional que define os princípios norteadores para a elaboração dos arcabouços legais normativos.

A Constituição Federal Brasileira - que completou 25 anos em 2013 -resultou de um intenso processo que mobilizou segmentos da sociedade organizada, cujo acúmulo, em muitos casos de décadas, foi traduzido no que se configura como a Constituição Cidadã, que tem o ideal de cidadania como horizonte norteador da reprodução social do espaço brasileiro. Talvez, não por acaso, seja este o contexto que esteja na base da demora, também de décadas, para regulamentação de alguns artigos das Constituição, como foi o caso dos artigos 182 e 183 que, regulamentados, deram corpo à Lei 10.257/01, Estatuto da Cidade.

Conforme já dito, é importante reconhecer que há atribuições que são de exclusividade de um dos entes federados, outras são privativas, outras são comuns ou concorrentes entre eles, podendo ser residuais e suplementares. Todavia, as atribuições possuem resultados cujo alcance e responsabilidades são sombreadas em mais de um ente federado. Há, portanto, a possibilidade de ocorrência de conflitos de interesses. Em situações como estas dirime-se sobre a constitucionalidade da ação sendo, que, no limite e nesta condição, prevalece o ordenamento definido em âmbito federal. Contudo, o que prevalece é o princípio da responsabilidade complementar e cooperativa entre os entes. Por exemplo, no artigo 24 da Constituição Federal são estabelecidas as competências da União, dos Estados e Distrito
Federal e Municípios. No item II de seu Artigo 30, o texto constitucional atribui aos Municípios - além da atribuição de legislar sobre assuntos de interesse local, a função de "suplementar a legislação federal e a estadual no que couber". Contudo, talvez pelo caráter colaborativo entre os entes, há também as situações que geram dúvidas sobre as respectivas responsabilidades. Tal situaçãoparece configurar-se no artigo Artigo 225 da Constituição, que trata em seu Capítulo VI sobre o Meio Ambiente. No artigo explicitado, há lacunas sobre as responsabilidades de cada uma das esferas de governo, cujo resultado éinsegurança ou imprecisão jurídica. Em um país de forte tradição no Direito Positivo, conforme destaca Montoro (2014), tal imprecisão cria uma lacuna que, em muito, aponta para situações conflituantes. Colocam-se, então, questões no centro dos debates, principalmente aquelas calcadas na definição das atribuiçõesnos temas ambientaisde responsabilidade exclusiva da União, dos estados, Distrito Federal ou dos Municípios.

Com relação à Política Urbana, mais afeita às reflexões que embasam este artigo, a Constituição Federal é mais específica, na medida em que nos Artigos 182 e 183 são mencionados alguns componentes legais e responsabilidades legisladoras, embora, como já citado, sua regulamentação tenha demorado mais de uma década. Para que como instrumentos legais tenham caráter normatizador, os artigos 182 e 183 foram regulamentados na forma da Lei Federal $\mathrm{n}^{\circ} 10257$ de 10 de julho de 2001, o chamado Estatuto da Cidade. A Lei 10257/2001 traz em seu escopo muito do acúmulo da luta em torno da reforma urbana, sendo que alguns seus instrumentos revelam o cerne da luta pelos limites à propriedade urbana e sua função social.

O contexto socioespacial que culmina no Estatuto da Cidade resultou de um intenso e extenso processo de urbanização brasileira levado a cabo pelo Estado a partir de 1930 quando a industrialização consolida-se como núcleo duro da reprodução ampliada da riqueza, induzindo à urbanização, com todas suas contradições. Entretanto, se a urbanização foi induzida, como necessidade da industrialização, também perpassa o processo histórico da reprodução das cidades - como prática ou ideal a ser alcançado - o sentido do encontro, de realização protagonista 
e autônoma do sujeito, o sentido reunião para realização do próprio viver humano. Enfim, da cidade como espaço de libertação.

Conforme demonstram os dados do Instituto Brasileiro de Geografia e Estatística (IBGE), no Brasil, mais de $80 \%$ das pessoas vivem em áreas urbanizadas, exigindo a concentração de esforços para oferecer vida digna para todos. Sobre a urbanização brasileira é preciso considerar sua característica diversa (e contraditória). Assim, têm-se cidades densamente urbanizadas e com nexos complexos, articuladas e mobilizadas diretamente para e pelos processos de reprodução ampliada da riqueza e há aquelas formas urbanas não (diretamente) mobilizadas e, entre estas, formas urbanas mediadoras.

Outra característica que marca o processo urbano brasileiro é o que Damiani (2000) denominou de urbanização crítica, que se caracteriza como um processo desigual e combinado da reprodução capitalista do espaço a partir dos elementos e relações que condicionam e se reproduzem no espaço urbano. Podemos afirmar, então, que temos na urbanização brasileira desde situações extremas das duas "pontas”, até estratificações, não raro, presentes no interior do mesmo espaço urbano. Fragmentos urbanos amplamente equipados que convivem e - talvez, mais que isso, sob a lógica capitalista de reprodução social do espaço - com fragmentos precários, submetidos a uma lógica perversa de reprodução. Mais do que os dois lados da mesma moeda, são fragmentos intrinsecamente conectados, cujos nexos fundamentam a reprodução ampliada da riqueza.

Como exemplos desta intrínseca e perversa conexão de fragmentos aparentemente tão distantes e diversos, destacam-se os exemplos de Uberlândia em Minas Gerais e de Rio Claro no estado de São Paulo, conforme o Atlas de Desenvolvimento Humano no Brasil (2013) e os dados do Censo Demográfico do IBGE realizado em 2010, que revelam espaços urbanos densamente urbanizados, com percentuais de urbanização que ultrapassam $97 \%$ de população urbana, mas com grande diversidade quanto aos acessos possíveis no interior de cada cidade. Considerando as características de uma urbanização relativamente recente (consolidada no final da segunda metade do século $\mathrm{XX}$ ) destacam-se os índices de urbanização alcançados nestes dois municípios que, afinal, deslindam parte relevante deste processo que vem ocorrendo no Brasil, considerando, principalmente, que estes municípios se configuram como espaços mediadores da inserção de lugares ainda não mobilizados diretamente à reprodução ampliada da riqueza.
Contudo, como se afirmou anteriormente, o "binômio industrialização-urbanização" foi, no Brasil, um projeto de Estado. Sua viabilização exigiu intensos fluxos migratórios a partir da década de 1930 , que encontram subsídios para o seu entendimento em alguns processos que, se guardam especificidades, são intrínsecos ao processo de modernização, conservadora, nos termos de Francisco de Oliveira (2003). Mas, em síntese, o que se destaca é que a formação dos núcleos urbanos e a necessidade do adensamento populacional foi uma imposição do processo de industrialização que trouxe a reboque o processo de urbanização que se, em princípio, induzido, assumiu a condição de indutor, de condição de principal fenômeno organização da reprodução social. Sob essa nova condição, a urbanização se ampliou e complexificou, alcança novas espacialidades, ampliando exponencialmente outras, base do que configurou como contradições de uma urbanização que, para muitos, revelou-se como perversa, precarizante e marginalizante, no bojo de qual nasceram as lutas pela Reforma Urbana no Brasil.

Contudo, tornar-se o fenômeno chave da reprodução social não situa a urbanização nos limites de suas próprias condições, mas também de outras que estão no cerne da reprodução capitalista do espaço. Assim, a imposição de intenso (e quase) compulsório processo de migração campo-cidade teve como uma de suas consequências fundamentais, o fortalecimento do processo de urbanização, que, crítica, traduz-se em imposição de condição marginal para grandes parcelas da sociedade brasileira, para as quais as promessas da modernidade ou mesmo da cidade que liberta não se realiza, não se materializa. Deste modo, há contingentes populacionais, compondo fragmentos urbanos que são amplamente integrados nos modelos de crescimento econômico nas cidades brasileiras e que fazem parte desses processos, ocupando e desempenhando funções para as quais oferecem sustentação ao sistema vigente. Por outro lado, há aqueles que só vivem esta realidade como negação, sobrevivendo dos resquícios do viver urbano, calcado na solidariedade ou capacidade criativa de improviso para a sobrevivência e pelo direito de (re)existir.

A reprodução capitalista do espaço - que tem na produção e organização do espaço, nos termos de Harvey (2005) - sua saída estratégica, embora não permanente, tem como principal a desigualdade socioespacial como fundamento de sua própria reprodução. Significa afirmar que a forma espacial produzida e organizada tem como fundamento atender as funções que vinculam à reprodução ampliada 
da riqueza em sua forma monetária o que, no limite, compõe a estrutura do espaço urbano, produzido para atender a interesses outros que não a reprodução social. Ou seja, a desigualdade socioespacial que se materializa no espaço urbano não é um efeito colateral ou resultante de um mau planejamento, é inerente e indissociável deste modelo de urbanização capitalista. É este fato que nos ajuda a compreender situações como, por exemplo, a irracionalidade da priorização do transporte privado sobre o público. Assim, pode-se dizer que os processos originam e são originados com funções e formas espaciais, ou seja, há uma relação capaz de criar atividades e suas materializações em territórios, cuja distribuição espacial constitui a construção organizacional dos espaços urbanos, que, por sua vez, se dão em uma sociedade econômica e socialmente estratificada.

Foi sob essas condições que os movimentos sociais brasileiros, entre os quais os movimentos de favelados, representações profissionais de geógrafos pela Associação dos Geógrafos Brasileiros (AGB), do Instituto dos Arquitetos do Brasil (IAB) compuseram, junto com os diversos segmentos da sociedade brasileira organizados, o que ficou conhecido como o Fórum Nacional pela Reforma Urbana (FNRU), participando de processos reivindicatórios com formulação de demandas que estimulam e promovem a participação popular. Conforme já foi dito, foi o acúmulo deste processo que culminou nos Artigos 182 e 183 e sua lei subsequente. E foi este contexto que fez com que a Lei 10.257/01 traduzisse em seu corpo normativo muitos dos anseios de segmentos populares que, no limite, se orientaram pela noção de $\mathrm{Di}$ reito Natural.

\section{0 estatuto da cidade}

O Estatuto da Cidade estabelece e regulamenta alguns instrumentos para garantir, se bem aplicados, no âmbito de cada município, o respeito ao direito à cidade bem como o cumprimento de sua função social e da propriedade. Nesta condição, este se torna um importante instrumento no contexto da reprodução do espaço urbano submetido aos preceitos da reprodução capitalista do espaço. Todavia, o mesmo também pode ser apropriado como instrumento de fomento a esta reprodução, o que indica que o campo de disputa não se encerra na regulamentação de artigos ou promulgação da Lei, mas se faz cotidianamente para que os normativos da Lei, em princípio progressistas, não sejam instrumentalizados para reafirmação de práticas urbanas conservadoras.
De fato, a Constituição Federal no parágrafo $2^{\circ}$ do Artigo 182 afirma que "a propriedade urbana cumpre sua função social quando atende as exigências fundamentais de ordenação da cidade expressas no plano diretor", o que remete para a importância dos planos diretores dos municípios. Se com essa argumentação fica explícita a importância de que os Municípios tenham seu Plano Diretor, o que talvez não se explicite tanto é que é na construção do mesmo que dá, mais do que a constituição de princípios normativos, a disputa pela cidade que se quer: seja reafirmando antigos princípios, conservando os termos de sua reprodução conservadora, seja pela introdução de princípios novos, à luz e em diálogo com os princípios da Cidadania que, no limite, norteiam a Constituição Cidadã que dá substrato a este instrumento. Desta maneira, a garantia da democratização nos municípios passa obrigatoriamente pelo desenvolvimento da cidadania e pela política que, por princípio, só se realiza no exercício participativo do poder pelo conjunto social.

A função social da propriedade e da cidade são temas afeitos ao Estatuto da Cidade que, embora não esclareça seus significados, abre o caminho para a luta pela justiça na ocupação dos espaços urbanos. Contudo, se o Estatuto é indicativo, este deve materializar-se enquanto possibilidade real no Plano Diretor dos municípios. Raquel Rolnik, na análise publicada em seu blog ${ }^{1}$, reflete sobre a relação entre os movimentos sociais organizados e as alterações no Plano Diretor, quando afirma que: “A sociedade foi às ruas porque quer viver numa cidade mais justa. Um dos caminhos para aproximar a moradia do trabalho é a garantia de que novos empreendimentos de alto padrão (que atende ao interesse de poucos) serão vinculados ao interesse de todos. É preciso iniciar o debate público da questão agora e construir coletivamente a melhor forma de aplicar a medida. A lei da solidariedade deve ser autoaplicável. Solidariedade já!".

0 estudo do Estatuto da Cidade requer que sejam identificadas diretrizes gerais a serem atendidas, envolvendo toda sociedade. Todas elas com possíveis e, em geral, necessárias adaptações às realidades diferenciadas entre municípios e entre as possíveis zonas que sejam identificadas internamente nas áreas urbanizadas. Os parâmetros e as diretrizes da política urbana brasileira apontam para instrumentos que o município pode utilizar de maneira a intervir nos processos de planejamento e gestão territorial urbana, garantindo ao cidadão o pleno exercício do direito à cidade. Para que isso

\footnotetext{
https://raquelrolnik.wordpress.com/tag/manifesto/
} 
seja possível, a lei incorpora a gestão democrática do município e especialmente da cidade, como resultado das lutas populares ao longo da história no Brasil. O plano diretor ao ser construído na perspectiva do Estatuto da Cidade se torna importante instrumento de "empoderamento" permitido pela "pactuação" dirigida às políticas de desenvolvimento inclusivo, o que, no limite, reafirma os princípios constitucionais norteadores dos termos democráticos das relações sociais. Os planos diretores em sua elaboração, acompanhamento de aplicação e fiscalização devem, assim, estimular a participação dos cidadãos, permitindo a produção coletiva, valorizando a criatividade com inovações a partir de situações concretas que se apresentam em cada município. Para isso são oferecidos os instrumentos necessários à sua elaboração e implantação com melhor compreensão do que é a função social da cidade, das propriedades, com distribuição dos benefícios e dos ônus da urbanização, permitindo assim a definição de políticas públicas que atendam ao interesse social. O Manifesto dos movimentos populares de São Paulo pode ser acessado no endereço https: //raquelrolnik. wordpress.com/tag/manifesto/ e demonstra que existe uma busca para efetiva aplicação do projeto contido no Estatuto da Cidade e, ainda, que este processo se dá de forma contínua e com envolvimento efetivo.

O planejamento participativo, abordado no Estatuto da Cidade deve ser adotado em todo o processo quando se pretende construir municípios melhores e mais justos. A participação cidadã é tratada como questão de princípio, a qual não se pode negligenciar. Para tanto há que se reconhecer que todos os cidadãos, mesmo aqueles que não trazem em sua formação a escolaridade formal - por vezes pela negação de direitos fundamentais a que foram submetidos - têm competências e conhecimentos para participar do planejamento municipal ou mesmo de sua cidade podendo intervir na realidade do lugar onde vivem, visto que trazem a experiência do viver na cidade, do lidar cotidianamente com suas questões. Em muitos casos, trazem a experiência da negação dos direitos que, no limite, é que se busca superar para que esta capacidade potencial se concretize na forma de ação participativa. Os processos de elaboração de planos e projetos têm de adotar metodologia em que todos os cidadãos acessem informações necessárias, de acordo com sua capacidade de entendimento. Mais que isso, que garantam o tempo necessário à discussão e elaboração de ideias e/ou princípios a serem resguardados neste instrumento normativo. Neste processo, pouco contribui a adoção de uma linguagem hermética ou tecnicista - que muitas vezes caracteriza a linguagem acadêmica - na medida em que não favorece a interação dialogada dos diferentes segmentos sociais. De fato, um dos princípios do Estatuto da Cidade é que a gestão dos municípios seja democrática com participação da população em geral e das entidades associativas presentes nos diversos segmentos sociais, de forma que a linguagem seja inclusiva e não se constitua em um campo de cerceamento à interação necessária. Também integra os objetivos deste processo o estímulo para a organização das entidades de representação social, de forma protagonista autônoma.

A garantia e a possibilidade de efetiva participação dos diferentes segmentos sociais, constitui-se, assim, em um grande desafio, se considerarmos que a sociedade brasileira vem de uma tradição de práticas autoritárias e fechadas à participação popular efetiva. Deste modo, é preciso ter em conta que o instrumento normativo por si só não é capaz de redefinir a forma da relação. De fato, sua necessidade é bastante indicativa de quão arraigadas são as práticas conservadoras, o que, por sua vez, indica os termos da disputa, os campos a se avançar e as possibilidades (e os limites) inscritos neste processo. Participar nas atividades de planejar e gerir as políticas territoriais urbanas e rurais demanda dos técnicos que coordenam e organizam o processo o efetivo dispor-se para a construção participativa, entendendo que o conflito, as posições divergentes, longe de se constituírem como entraves, são possibilidades de busca de uma síntese superior às posições individuais ou de segmentos de grupos, em prol da coletividade.

Neste sentido, a valorização das diversidades deve se constituir princípio fundamental para reger as definições das políticas públicas e suas intervenções nos lugares, sendo estes resultados de um processo construído, inclusive, com as pessoas do lugar. Ressalta-se, porém, que não há uma fórmula única e salvadora para que seja aplicada em todos os municípios se, mesmo, em um município como todo. Ao contrário, é da diversidade advinda da rica prática social que se materializa aquilo que é específico, mas que tem a força de retroalimentar os princípios norteadores, inclusive para revisões, aperfeiçoamento dos instrumentos normativos, quando assim for necessário. Conforme indicado pela estrutura jurídica da Federação, o Plano Diretor deve ser discutido e aprovado pela Câmara de Vereadores e sancionado pelo Prefeito de cada município. O resultado é formalizado como Lei Municipal pactua- 
da e firmada entre a sociedade e os poderes Executivo e Legislativo. Contudo, sua preparação deve resultar de um acordo construído em articulação com as comunidades, considerando-se os processos participativos expressos. O planejamento dos espaços municipais, especialmente das áreas urbanizadas, como todos os objetos sociais, pode ser abordado na perspectiva de um paradigma de conflitos, de construção de acordos e eventualmente por consenso.

Embora o Plano Diretor seja de âmbito do município, a União e os estados devem participar no processo de preparação dos Planos Diretores, tendo em vista interesses regionais e nacionais, bem como a complexidade que envolve a urbanização brasileira e, ainda, o pacto federativo que envolve as três escalas do poder estatal. Os Planos Regionais, de responsabilidade dos estados devem oferecer balizamento para que sejam considerados pelos municípios em seu esforço de preparar o Plano Diretor integrando as políticas públicas. Essa necessidade deve ser reconhecida em sua mão dupla, pois é indispensável que os estados e Distrito Federal reconheçam os Planos Diretores Municipais para a elaboração de seu planejamento. Em outras palavras o Planejamento deve ser feito de maneira a integrar e valorizar as demandas e alternativas apresentadas pelos entes federados, de forma que os planos regionais traduzam as questões e princípios respaldados nos diversos planos diretores dos Municípios que integram efetivamente a região objeto do planejamento regional.

A construção e elaboração do Plano Diretor de cada município deve constituir-se em incentivo para a realização de avaliações que viabilizem a implantação de todo o sistema de planejamento municipal integrado. Um dos problemas para o planejamento urbano e também rural diz respeito à necessidade de atualização dos cadastros da estrutura fundiária. A maioria dos municípios não conhece quem são os proprietários dos solos e nem a real extensão das propriedades, sejam elas públicas ou privadas. Revela-se, então, não apenas um importante campo de pesquisa que tenha os aspectos histórico-geográficos como objeto de investigação científica, mas principalmente, a necessidade da constituição de um banco de dados confiável e preciso, visto que o conhecimento da propriedade - dimensão, propriedade, localização - está no cerne do Estatuto da Cidade. Esta deve ser uma exigência para com todo o município, no sentido de se estabelecer uma pesquisa cartorial efetiva para a construção da informação confiável e balizar do processo do processo em questão, inclusive garantindo a acessibilidade necessária à informação. Pesquisas, como a realizada por Ario- valdo Umbelino Oliveira, indicam discrepância entre a soma das propriedades - quase sempre maior - que a área real do município, considerado seus perímetros rurais e urbanos estabelecidos em lei. Daí que a construção de um cadastro mais próximo da realidade seja uma tarefa indispensável para o bom planejamento municipal.

Da mesma forma, os diversos setores das administrações dos entes federados possuem estruturas organizacionais e zoneamentos que não se relacionam entre si. Por exemplo, os setores da educação, saúde, segurança pública, transporte, obras públicas, saneamento básico entre outros, possuem inserções e "territorializações" diferentes no espaço municipal e em geral não dialogam entre si. Para o Planejamento é necessária a busca de compatibilização dos processos de organização para atualizar os cadastros, integrando as políticas setoriais, articulando seus orçamentos anuais e plurianuais com os planos de governo e com as diretrizes do Plano Diretor, capacitando continuadamente as equipes que poderão melhorar, sistematizar e consolidar a legislação. A elaboração do planejamento é uma oportunidade para serem estabelecidos processos permanentes de construção das políticas que avaliam e corrigem os rumos de políticas municipais.

Democratizar as decisões é fundamental para transformar o planejamento da ação municipal em trabalho compartilhado entre os cidadãos, entidades públicas e privadas sendo assumido por todos, bem como para assegurar que haja o sentido de pertencimento e o comprometimento com as responsabilidades exigidas no processo de implementação de suas premissas estabelecidas e pactuadas. 0 controle e a fiscalização das atividades permitem o reconhecimento, se for o caso, do cumprimento dos pactos realizados bem como a avaliação das atividades públicas e privadas. Tais verificações permitem o acompanhamento e o estímulo ao desenvolvimento de ações integradas, por dentro do governo e com os demais produtores do espaço municipal, garantindo um sistema de participação que seja capaz de legitimar ações governamentais.

Todos esses elementos demonstram a necessidade de que as ações sejam praticadas por dentro das administrações municipais, com as devidas capacitações que orientam na direção do objetivo de praticar o Planejamento Participativo. O trabalho de capacitação deve ser contínuo e desenvolvido no processo de formação da cidadania, envolvendo todos os sectores públicos, privados e da sociedade civil. Torna-se indispensável a cooperação da administração municipal com as demais esferas e diferentes níveis 
de governo, com a iniciativa privada e todos os setores sociais que estão inseridos nos municípios e nos seus entornos regionais, buscando o atendimento dos interesses sociais.

Para cumprir o que está estabelecido no Estatuto da Cidade os planejamentos devem considerar e buscar alguns princípios fundamentais como a garantia do exercício do direito a cidades sustentáveis. A sustentabilidade aqui tratada não diz respeito à manutenção/sustentação do atual status quo, mas à sustentabilidade da vida e do lugar, implicando o respeito aos direitos dos cidadãos, o que inclui demandas ambientais com promoção social e econômica de seus atores e agentes. Por exemplo, quando se trata do assunto habitação, não se pode prover apenas o embrião residencial, mas há que se garantir as condições para que se sustente uma forma digna de viver, considerando os aspectos ambientais, econômicos, com a amplitude dos componentes sociais. No município de São Paulo, movimentos sociais urbanos se reuniram para produzir um Manifesto no qual expressam“.0 Plano deve incorporar as diretrizes colocadas na Portaria $n^{\circ} 17 / 2013$ do Ministério das Cidades, e todos os princípios para garantia da moradia adequada e segurança na posse, evitando que as obras públicas ou privadas impliquem deslocamentos forçados ou involuntários de famílias moradoras em favelas ou loteamentos populares, devendo ser previstas todas as medidas necessárias para garantir a moradia digna e participação dos interessados em todas as etapas do processo."

A moradia - direito de todo cidadão, se considerarmos os preceitos do direito fundamental respaldado na Constituição Federal - é, em geral, tratado como conquista. Não por menos, tende a ser mais festejada, considerando que para parcela considerável da sociedade brasileira este projeto demanda o direcionamento de recursos ao longo de muitos anos. Porém, esta não pode se resumir a um equipamento para a simples realização da função morar. Nesta condição, o habitar, o viver, como direito, é reduzido a uma de suas dimensões, o funcional, acarretando, porém, perdas do morar no sentido do experimentar. 0 habitar, então, cede lugar ao habitat, como bem definiu Henri Lefebvre (1999). À moradia é essencial que se somem os chamados equipamentos e serviços urbanos comunitários, que atendam as necessidades das populações, com justa distribuição dos benefícios e dos ônus, assim como protegendo, preservando e recuperando as características do meio ambiente natural e cultural.

A condição desigual e estratificada da sociedade brasileira exige, porém, formas diferenciadas no modo de lidar com os segmentos sociais, no sentido de alcançar o princípio de equidade. Assim, a sustentabilidade no município exige do poder público que sejam priorizadas as populações fragilizadas que vivem em condições de precariedade habitacional em função dos rendimentos obtidos. Em geral, são populações que ocupam áreas identificadas como de risco, portanto inapropriadas para o habitar, por uma aparente incapacidade do "sistema" de incluí-las na chamada "cidade formal" mas, fundamentalmente, porque o reverso da reprodução ampliada da riqueza é a negação da realização da mesma para muitos que integram, marginalmente, a cidade.

\section{Considerações acerca do plano diretor de Uberlândia}

Conforme já referido, a elaboração do Plano Diretor não é um presente do legislativo e executivo para os habitantes do município. Ao contrário, o mesmo dever resultar da construção coletiva em cujo processo sejam mediados os conflitos resultantes de uma sociedade estratificada e desigual e cujo instrumento se norteie pelos princípios da realização da cidadania. O Plano Diretor é assim, um instrumento normativo que se constitui em obrigatoriedade do município de criar as condições para sua construção participativa. Assim, cabe aos municípios organizar o processo de elaboração e atualização nos períodos definidos em Lei. Tal condição implica na preparação do planejamento territorial onde se define o melhor modo de ocupar o sítio do município ou região, prevendo os pontos onde se localizarão atividades e os usos do espaço no presente e no futuro. O plano diretor é, então, um instrumento básico indispensável para definição da política de desenvolvimento urbano e do município que, integrado com o Plano Plurianual (PPA), com as diretrizes orçamentárias e com orçamentos anuais, constituem importantes instrumentos da governabilidade no que se refere ao espaço urbano.

Identificar quem e quais são os setores que produzem os espaços urbanos e os restantes do município é também uma tarefa premente dos legisladores e de todas as comunidades para que os trabalhos de planejamento e gestão considerem os interesses gerais e setoriais, na perspectiva da função social da cidade. Para Roberto Lobato Corrêa (1995), são os seguintes os agentes que produzem e reproduzem a cidade: a) os proprietários dos meios de produção, sobretudo os grandes industriais; b) os proprietários fundiários; c) os promotores imobiliários; d) o estado em todos os níveis e esferas; e) os grupos sociais incluídos ou marginalizados no espaço urbano. 
A estes, podemos somar os setores representativos de trabalhadores, patronais e as Mídias e imprensa em geral. A todos estes, com posições por vezes antagônicas, há que se garantir a participação na elaboração do Plano Diretor. Assim, um plano participativo efetivamente exige a identificação e mobilização destes segmentos, como instrumento de legitimação do mesmo, levando para o seu interior as discussões e enfrentamentos colocados para a reprodução do espaço urbano nos termos apontados pela legislação pertinente. Desta maneira, é preciso o entendimento de que cada um dos segmentos desses agentes têm interesses próprios, legítimos ou não. Mas, principalmente, que os princípios norteadores são aqueles expressos no texto constitucional e no Estatuto da Cidade. A abertura do diálogo com base em princípios democráticos de participação poderá ajudar substancialmente para que fiquem explícitos tais interesses. Neste aspecto, a adoção de metodologia que permita o debate e que as decisões sejam tomadas coletivamente constitui uma rica possibilidade de avanços dirigidos à valorização da função social da propriedade e da cidade.

De acordo com o Ministério das Cidades e o CONFEA (2004), pelo planejamento territorial podem-se concretizar na cidade os benefícios para todos: por intermédio da democratização das oportunidades para todos os moradores; pela garantia das condições satisfatórias para financiar o desenvolvimento municipal; e pela democratização das condições para uso dos recursos disponíveis, de forma sustentável. É claro que essa intenção do Ministério das Cidades ainda não se concretizou e nem tem data marcada para acontecer, principalmente pensando em todos os embates e conflitos entre os entes federados e as características das gestões municipais que são administrados no modelo capitalista. Ainda assim, a redução dos impactos negativos sobre as vidas são merecedoras de esforços e se constituem na obrigação das administrações públicas, da iniciativa privada e de todas as pessoas que vivem nos municípios.

Efetivamente, o primeiro passo, em todos os municípios, é conhecer e mapear a estrutura fundiária, a realidade social e suas tendências de desenvolvimento num modelo em que não vigora efetivamente o controle social. Nas atuais estruturas capitalistas em que prevalecem os interesses de auferir ganhos no jogo com a propriedade com vistas à extração das rendas fundiárias, este mapeamento revela-se com elevado grau de realização. Ainda assim, compete às estruturas municipais a obrigação de conter e atualizar tais registros e, a partir desse conhecimento, definir os instrumentos previstos no
Estatuto da Cidade que mais favoreçam a priorização da função social sobre a propriedade, inclusive garantindo instrumentos e ações necessárias para a regularização fundiária a partir da realidade dada em cada município. Por exemplo, há situações em que seria adequado o processo de urbanização de favelas. Em outros casos é possível que seja necessária a realocação das populações que habitam em áreas sujeitas a riscos ambientais. Contudo, como afirma o movimento social no manifesto da cidade de São Paulo: "por uma Cidade sem despejos ou remoções forçadas", ou seja, em situações como estas a construção participada das estratégias adotadas para a resolução dos problemas. A existência de um planejamento participativo certamente minimizará muitos dos conflitos que são registrados nas cidades brasileiras, causados por ações autoritárias e compulsórias.

Nos espaços urbanos, o Imposto Predial e Territorial Urbano (IPTU) é calculado levando em conta o tamanho do terreno e das áreas construídas. Contudo, em muitos casos, o cadastro territorial e predial não são atualizados. Novas construções, ampliações e reformas, em muitos casos são realizadas sem que a municipalidade tenha qualquer conhecimento ou emitido a licença necessária. Assim é que residências ampliadas com, por exemplo, construção de piscinas e amplas áreas de lazer ficam em situação de irregularidade, com a devida conivência dos poderes públicos, inclusive sem a tributação devida, situação que, em geral, perpassa praticamente todas as classes sociais.

Assim, um aspecto importante na elaboração do Plano Diretor é a perspectiva de reformular e, quando for o caso, consolidar legislação de parcelamento, uso e ocupação do solo e do código de obras que definirá as normas de edificações, a partir da atualização do cadastro municipal. Isso porque, o cenário de "confusão legal” ou informação imprecisa ou não atualizada favorece aos chamados setores especuladores da terra urbana, capazes de dialogar em "situações especiais" com os administradores municipais. Para quem deseja cumprir as funções sociais das propriedades e da cidade, um conjunto de normas que tenha clareza e consistência e informações atualizadas, ajuda no processo de planejar investimentos, oferecendo segurança jurídica para empreendimentos individuais e empresariais.

Contudo, tais procedimentos para organização da legislação de parcelamento e construção nem sempre são realizados com facilidade, em função da diversificação dos interesses que se contrapõem nos espaços urbanos. A economia política das cidades 
geralmente é conduzida por interesses que fazem dos espaços urbanos seus negócios. Os interesses econômicos geralmente estão submetidos ao setor imobiliário e as empreiteiras de obras públicas e concessionárias de serviços públicos. Por exemplo, os proprietários de terras exercem suas influências para a obtenção da elevação da renda fundiária em suas modalidades possíveis, empreiteiros normatizações mais permissivas e assim sucessivamente. Neste jogo, utilizam-se forças sociais, econômicas e políticas para imposição das condições favoráveis aos seus interesses. O sentido geral é que estes "socializam os investimentos para privatizar os lucros", se aproximando e articulando com esferas de que permitem este tipo de ação. Tais processos especulativos devem ser entendidos pelos administradores públicos responsáveis pela aprovação de parcelamentos do solo urbano, bem como a democratização do processo de planejamento poderá posicionar em torno de uma mesa de negociação, todos os setores envolvidos em promovera urbanização. Com isso, muitos dos processos autoritários, típicos da urbanização que se orientada pela reprodução da riqueza podem, minimamente, ser contidos em função do interesse social, embora não seja o que prevaleça contemporaneamente, mesmo após uma década de Estatuto da Cidade.

Entretanto, ações que visam romper ou minimizar a prevalência da acumulação em detrimento do interesse social demandam um aprofundamento na compreensão da função social da cidade sem que haja simplificações que reduzam os significados dos fatos e das ações. Assim é que concordamos com Edgar Morin, 1995, p. 118, ao afirmar “Hay que recordar las ruinas que las visiones simplificantes han producido, no solamente em el mundo intelectual, sino también em la vida”.

\section{Estatuto da Cidade e Planos Diretores de Uberlândia} e Tupaciguara, MG.

O Plano Diretor de Uberlândia constitui a Lei Complementar $\mathrm{N}^{\circ} 432$ de 19 de outubro de 2006 e caracteriza-se, em certo sentido, como um documento genérico e passagens como em seu Artigo $2^{\circ}$ ao definir-se como instrumento: “Plano Diretor é o principal instrumento da política de desenvolvimento urbano e ambiental de Uberlândia, tendo por objetivo orientar a atuação do Poder Público e da iniciativa privada, bem como atender às aspirações da comunidade, constituindo-se na principal referência normativa das relações entre o cidadão, as instituições e o meio físico".
Sua preocupação ambiental está claramente expressa no Artigo referido e consolidada no Art. 16, ao afirmar que "São diretrizes para a área rural, do Município de Uberlândia:

I. elaborar planejamento ambiental do Município e de suas bacias hidrográficas, de acordo com a legislação pertinente;

II. empreender esforços para a criação de Área de Proteção Ambiental - APA - estadual junto às Bacias dos Rios Uberabinha e Bom Jardim”.

Reafirmando os princípios estabelecidos no Artigo 16, o Plano Diretor de Uberlândia expressa ainda: Art. 22. Para fins de uso e ocupação do solo o macrozoneamento do Município de Uberlândia será dividido na forma do Anexo I desta Lei Complementar, com o seguinte detalhamento:

I. Macrozona de Proteção das Áreas dos Mananciais - MZP: esta Zona contempla áreas da micro bacia do Rio Uberabinha e do Ribeirão Bom Jardim, com o intuito de proteger essas microbacias à montante das captações;

Embora estar expresso no Plano Diretor seja uma etapa importante, seus dispostos tornam-se genéricos ou apenas intenções, caso não se consolidem nas práticas das ações e projetos. Um bom exemplo da distância entre o que aparece como intenção e prática efetiva é o processo que envolve o Comitê de Bacia Hidrográfica do Rio Araguari (CHB-Araguari).

No ano de 2012, o CBH-Araguari criou um Grupo de Trabalho (GT) para propor a criação da Área de Proteção Ambiental da Chapada dos Bugres, envolvendo o alto Curso do rio Uberabinha, incluindo o Bom Jardim. Ressalte-se que tais corpos de água superficiais são exatamente os provedores de água para captação e abastecimento de toda a população urbana da sede municipal. A Prefeitura Municipal de Uberlândia e o Departamento Municipal da Água e Esgotos (DMAE) participaram do GT até o último momento, contribuindo por intermédio de seus técnicos com todo o processo elaborado. Na Reunião em que o $\mathrm{CBH}$-Araguari submeteu ao seu Plenário o encaminhamento da proposta para a Secretaria Estadual do Meio Ambiente de Minas Gerais, a Prefeitura e o DEMAE não só votaram contra a iniciativa como se articularam com outras prefeituras, com os produtores do complexo agroindustrial e indústrias de extração mineral para garantir a não aprovação. Trata-se de uma postura política que contradiz a visão técnica e participativa, ao mesmo tempo em que consolidam posturas conservadoras, em uma nítida demonstração de que não adianta apenas a 
existência de um Plano Diretor que trata dos temas de maneira adequada aos interesses públicos, mas do engajamento efetivo de seus representantes para cumprir e fazer cumprir o que está expresso o que foi construído coletivamente. Observa-se que os poderes constituídos nem sempre estão livres ou são capazes de contrapor as pressões de setores que em verdade possuem maior controle de suas decisões. Geralmente são mais passíveis de vitória as concepções dos setores privilegiados economicamente, que se atribuem as funções de provedores do trabalho e geração de renda municipal, por exemplo. Estes embates são comuns nos municípios e somente poderão ser confrontados em processos nos quais a sociedade organizada explicite tais interesses que não atendem a vontade dos cidadãos. O Estatuto da Cidade traz em si instrumentos importantes que guardam relação com a efetivação das políticas de colaboração e indução ao desenvolvimento urbano. A partir dele e em sua plena e efetiva participação, é possível que situações como a citada ganhem outras instâncias e condições de negociação mais vinculadas ao interesse social coletivo.

Dentre os dispositivos do Estatuto da Cidade, alguns merecem destaque, especialmente aqueles relativos ao parcelamento, edificação ou utilização compulsórios; ao imposto sobre a propriedade predial e territorial urbana progressivo no tempo; à desapropriação para fins de reforma urbana; ao consórcio imobiliário; às operações urbanas consorciadas; ao direito de preempção e a outorga onerosa do direito de construir.

O parcelamento do solo e a edificação compulsórios são instrumentos disponíveis ao poder público municipal, como forma de garantir que os proprietários de imóveis urbanos os utilizam de acordo com a função social prevista no Plano Diretor. Com esse instrumento o poder público poderá exigir que a edificação se concretize, limitando a permanência de terrenos como reserva de valor, à espera da valorização do espaço decorrente da própria dinâmica da cidade. A efetividade deste instrumento traduz uma necessidade da urbanização brasileira, na medida em que nas cidades brasileiras permanecem grandes "estoques" de terrenos ociosos, inseridos nos perímetros urbanos, aguardando a valorização fundiária e deixando de cumprir suas funções sociais, onerando o município. Isso porque, a não utilização desses "vazios urbanos" acarreta necessidade de incorporar novas áreas nos perímetros urbanos, ampliando os custos de investimentos em obras que acabam assumidos por recursos públicos.
Tratando desse instrumento de política urbana, a Lei 432/2006 de Uberlândia assim se expressa:

“Art. 47. O parcelamento, a edificação e a utilização compulsórios do solo urbano visam garantir o cumprimento da função social da cidade e da propriedade, por meio da indução da ocupação de áreas vazias ou subutilizadas, onde for considerada prioritária a densificação, na forma de Lei específica dispondo sobre a matéria”.

A abordagem demonstra que o legislador municipal declara a pretensão de promover o adensamento para reduzir os custos da reprodução da cidade, trazendo os benefícios inerentes aos objetivos do Plano. Contudo, as práticas adotadas pelas legislações que se sucederam e presentes na aprovação e implantação de parcelamentos do solo urbano, bem como edificações residenciais, caminhou em sentido diferente. 0 que se percebe, de 2006 aos dias atuais, foi a implantação de Conjuntos Habitacionais em setores distantes da cidade, como o conjunto de oito empreendimentos do Programa Minha Casa, Minha Vida, implantados no extremo limite do bairro Park Shopping. Empreendimentos como este demonstram como, afinal, os conjuntos habitacionais continuam cumprindo a função conservadora e de lógica invertida como "indutores da urbanização", posto que sua instalação exige que o poder público estenda até mesmo os serviços urbanos públicos. Ao fazê-lo, os terrenos não edificados presentes "entre" a cidade, no conjunto, são valorizados pela instalação destes serviços. Cada vez mais, os segmentos sociais submetidos a esta condição de acesso à moradia veem-se diante de uma contradição fundamental: o acesso a moradia thes permite o direito à cidade. Todavia, nos termos em que se dá, ao obterem o que Ihes dá acesso, a forma lhes nega a própria cidade, visto que, a distância e a precariedade se somam a outros entraves concretos e simbólicos que vão se erguendo como obstáculos ao efetivo direito à cidade.

Este processo, identificado no Plano Diretor de Uberlândia, também se registra em outras Leis elaboradas pelos municípios que estão nas suas proximidades geográficas. Exemplo dessa disposição registra-se no Plano Diretor de Tupaciguara, instituído pela lei complementar № $96 \backslash 2007$ com aplicação a partir do ano de 2007. Há indicação do interesse em cumprir a determinação legal contida no artigo 182 da lei federal $N^{\circ}$ 10.257. Contudo, o Plano Diretor carece de legislação complementar para que seja eficaz. O instrumento Parcelamento do Solo, Edificação e Utilização Compulsórios, foi tratado na seção I do capítulo II, destinado à abordagem sobre o cumprimento da função social da propriedade urba- 
na. No Art. 56, o município explicita que promoverá a ordenação do uso e ocupação do solo de acordo com as seguintes diretrizes: integração e complementaridade entre as atividades urbanas e rurais tendo em vista o desenvolvimento sócio-econômico sustentável; planejamento do desenvolvimento, da distribuição espacial da população e das atividades econômicas de modo a prevenir e a corrigir as distorções do crescimento urbano; oferta de equipamentos urbanos e comunitários, transporte e outros serviços públicos adequados aos interesses e necessidades da população e às características locais; justa distribuição dos benefícios e ônus decorrentes do processo de urbanização; proteção, preservação e recuperação do meio ambiente natural e construído, do patrimônio cultural, histórico, artístico e paisagístico; e gestão democrática por meio da participação da população. Para cumprir estas funções, o Artigo 57 estabelece que o uso e a ocupação do solo no município de Tupaciguara serão regulamentados pela Lei Complementar de Parcelamento, Uso e Ocupação do Solo, que deveria ser elaborada e aprovada até 31 de março de 2008, fato que ainda não ocorreu. A intenção demonstrada no texto legal não se transformou em matéria de efetiva aplicação tendo em vista a falta das normatizações complementares e suplementares.

A não efetividade desse instrumento, embora previsto nas normativas, é um bom indicativo do campo de disputa existente no âmbito da reprodução social do espaço urbano, em que a lógica progressista se depara, constantemente, com os entraves das práticas que visam conservar os termos históricos dessa reprodução.

Outro instrumento importante do Estatuto da Cidade é a possibilidade da instituição do IPTU progressivo. Este instrumento, além de estimular a edificação e induzir à desconcentração, tem o condão de possibilitar a distribuição justa da riqueza inerente à propriedade para cumprimento de sua função social. 0 imposto sobre a propriedade predial e territorial urbana poderá ser progressivo em razão do valor do imóvel e definir alíquotas diferentes de acordo com a localização do imóvel no espaço urbano. A aplicação do IPTU Progressivo no tempo exige que as áreas a ele submetidas sejam indicadas e identificadas no Plano Diretor, que leve ao cumprimento das obrigações do proprietário no prazo de cinco anos. Em caso de não cumprimento, a alíquota elevada assim permanecerá até o cumprimento da obrigação ou à possível desapropriação do imóvel, com o objetivo de promover a reforma urbana. Todavia, o que se tem observado é a não aplicação deste instrumento ou a definição de percentuais progressivos tão irrelevantes que faz com que 0 instrumento não cumpra seu potencial.

No Plano Diretor de Uberlândia, nos Artigos de 52 a 54 está disposto este instrumento. Contudo a prática não demonstrou operacionalidade, pois não houve legislação específica que regulamentasse exatamente em que setores seriam adotadas tais providências. Neste sentido, a generalização presente no Artigo 54, evidencia a não determinação dos locais sujeitos para produzir os efeitos de aplicação, inclusive para que possam ser adotadas as necessárias providências de informar os munícipes que serão abrangidos pelo instrumento proposto. Desta maneira, o que se alcança é a não implantação. No referido artigo está expresso que "o IPTU Progressivo no Tempo poderá ser aplicado em todo o perímetro urbano, em conformidade com o estabelecido em lei específica". É nítido como a expressão final "o estabelecido em lei específica" coloca a condição de não execução imediata, estendendo no tempo aquilo que a própria luta urbana já aponta como uma questão necessária aos termos da urbanização contemporânea.

No Plano Diretor do município de Tupaciguara este instrumento também é tratado na Seção II, Capítulo II, sem a objetivação de resultados. Assim, segundo o Art. 114, em caso de descumprimento das condições e dos prazos estabelecidos para o parcelamento, edificação ou utilização compulsória, o Município aplicará o IPTU progressivo no tempo, mediante o aumento da alíquota pelo prazo de 5 (cinco) anos consecutivos, até que o proprietário cumpra com a obrigação de parcelar, edificar ou utilizar, conforme o caso. Tal como no caso de Uberlândia, para que esta intenção seja aplicada seria necessário que as áreas objeto do instrumento estivessem indicadas no Plano Diretor ou em Lei Complementar, para que assim seja exigido o cumprimento de obrigação por parte dos proprietários dos imóveis. Também em Tupaciguara a delimitação das áreas sujeitas à aplicação do instrumento legal não foram definidas.

Também constante no Estatuto, a desapropriação em utilização de títulos da dívida pública viabiliza a desapropriação das propriedades que não estiverem em consonância com a função social da propriedade registrada no Plano Diretor. Após a decorrência de cinco anos de aplicação do IPTU Progressivo no Tempo, caso o proprietário não tenha destinado função social ao imóvel, o poder público poderá emitir Títulos da Dívida Pública, com aprovação do Senado Federal em prazos de resgate de 
até 10 anos. Este instrumento, em conjunto com o IPTU Progressivo no Tempo, identificando os locais onde serão aplicadas as edificações compulsórias, configura-se como excelente estratégia do poder público para garantir o cumprimento da função social da propriedade e da cidade. Na Lei 432/2006 de Uberlândia o assunto tem capítulo especial no qual conclui afirmando

Art. 57. A Desapropriação com Títulos da Dívida Pública poderá ser aplicada em todo o perímetro urbano, sendo que as áreas prioritárias para aplicação desse instrumento serão aquelas definidas para o parcelamento, a utilização e a edificação compulsórios, sem prejuízo de outras que venham a ser classificadas pelo Conselho Municipal do Plano Diretor, em legislação específica.

Mais uma vez fica expresso o interesse de não aplicar o instrumento, na medida em que ficam indefinidos os parcelamentos e parcelas do solo urbano que poderão ser submetidos ao dispositivo. Principalmente, quando determina a necessidade de ser elaborada legislação específica para o cumprimento da norma, sendo esta iniciativa postergada enquanto no embate político as forças continuam pendendo para o mesmo lado... Possibilita-se, no limite, que, mesmo indicando medidas de interesse social, elas ficam confinadas aos interesses dos proprietários do solo urbano e das empresas imobiliárias. Já no município de Tupaciguarao tratamento deste instrumento também está inócuo, possivelmente pelo mesmo embate de forças. Segundo o Art. 116 do Plano Diretor, decorridos cinco anos de cobrança do IPTU progressivo sem que o proprietário tenha cumprido a obrigação de parcelamento, edificação ou utilização, o Município poderá proceder à desapropriação do imóvel, com pagamento em títulos da dívida pública. Contudo, não são indicadas as áreas sujeitas ao IPTU progressivo no tempo, o que impede sua aplicação e os desdobramentos ali expostos.

Os Consórcios Imobiliários são outro instrumento oferecido pelo Estatuto da Cidade, que prevê a possibilidade do estabelecimento de consórcios imobiliários, permitindo a cooperação entre o poder público e a iniciativa privada para fins de urbanização. As áreas destinadas a esta aplicação devem estar relacionadas no Plano Diretor e projetadas para o oferecimento de infraestrutura e serviços urbanos. Assim, o proprietário da terra oferecerá parte da área para que o poder público implante, por exemplo, projetos de lotes urbanizados para assentar parte dos interessados ou mesmo para comercializá-los. Essas operações urbanas são consorciadas e, por intermédio de lei municipal, permitem intervenções urbanas com parceria entre o poder público e a iniciativa privada. Toda a operação deve ser coordenada pelo poder público, preservando o interesse social. As áreas onde se pode aplicar este instrumento devem ser destacadas no Plano Diretor com detalhamentos efetuados por lei específica permitindo o consorciamento entre o município, os proprietários de terras, as empresas que farão os investimentos e moradores, quando for o caso. Para ter recursos financeiros nestes processos o município está autorizado a emitir certificados de potencial adicional de construção, que poderão ser alienados em leilão ou utilizados para pagamento das obras previstas na operação. As leis específicas e regulamentadoras deverão conter as normas, prevendo estudos sobre os impactos dessas operações. Deverão prever também as modificações de índices de ocupação com as características do parcelamento, o uso e ocupação do solo, bem como as alterações nas normas de edificação e os consequentes impactos positivos e negativos que serão causados pelos empreendimentos. Todo o processo precisa garantir benefícios sociais e econômicos para as populações diretamente afetadas. Assim é que os Projetos de Leis complementares deverão apresentar uma exposição de motivos que justifique a aplicação do instrumento legal e a lisura das relações entre o setor público e a iniciativa privada. Todavia, o que se tem observado em municípios maiores é que os chamados consórcios imobiliários são constituídos em importante instrumento de revalorização do espaço, reforçando os termos conservadores da urbanização, em detrimento da função social da propriedade. Em Uberlândia, tais estratégias ainda não foram adotadas, embora setores centrais já começam a despertar interesses da indústria da construção civil neste sentido.

O Direito de Preempção permite ao município mais uma base legal de preferência para obter e comprar determinados imóveis, ainda que a propriedade esteja em processo de alienação para outro comprador. Esse direito poderá ser exercido sempre que a propriedade se enquadre nas diretrizes definidas para a política urbana do município e nos critérios estabelecidos no Plano Diretor. Contudo, o município expressará em lei esse direito que poderá ser exercido pelo prazo máximo de cinco anos. Para o bom cumprimento dessa lei, o proprietário do imóvel, sempre que pretender aliená-lo, terá que informar o poder púbico. Se houver alguma proposta para compra do imóvel, há necessidade de ser incluída uma cópia, devidamente validada pelo interessado. 0 poder público terá o prazo de trinta dias para se definir pela preferência e compra. Caso 
contrário o proprietário estará liberado para efetuar a venda prevista na proposta apresentada. A preferência poderá ser exercida por interesses mútuos do proprietário e do poder público, mas também poderá ser exercida de maneira unilateral. A lei municipal que estabelece o direito de preempção precisa enquadrar as áreas sujeitas à sua aplicação e apontar as finalidades, sob pena de não ter eficiência jurídica.

O Plano Diretor de Tupaciguara aborda o direito de Preempção com o seguinte conteúdo no Art. 130, afirmando que: “...o Município poderá exercer seu direito de preempção nas áreas inseridas nas seguintes zonas: Zona de Adensamento Preferencial (ZAP); Zona Central (ZC); Zona de Expansão Urbana (ZEX). No $\$ 1^{\circ}$, a Lei específica que relacionará todas as glebas e lotes, com edificações ou não, onde se aplicará o instrumento e estabelecerá os prazos e condições para a implementação das medidas por parte dos proprietários; afirma no $\$ 2^{\circ}$ que o prazo de vigência do direito de preempção não poderá ser superior a 5 (cinco) anos, renovável a partir de um ano após o decurso do prazo inicial de vigência; e no $\$ 3^{\circ}$ assevera que o direito de preempção fica assegurado durante o prazo de vigência fixado na forma do $\$ 2^{\circ}$, independentemente do número de alienações referentes ao mesmo imóvel."

Mais uma vez, a efetividade da Lei está submetida à elaboração de Lei específica o que até o momento ainda não ocorreu.

Esta parece ser uma constante nos Planos Diretores que foram elaborados, obedecendo às exigências legais. Será necessário que esse roteiro seja revisto com a elaboração das normas que thes garanta a efetiva funcionalidade.

Pelo solo criado, ou outorga onerosa do direito de construir, a legislação municipal deve estabelecer um coeficiente básico de aproveitamento dos terrenos. Caso ultrapasse esse limite poderá - havendo previsão legal, na qual o proprietário ofereça contrapartidas - obter este direito em função do interesse público. Ocorre que com o aumento do coeficiente acontecerá um maior adensamento na área, obrigando que o poder público efetue novos investimentos, elevando-se os custos econômicos. A análise a respeito dos limites impostos pela infraestrutura instalada e as consequências com esse maior adensamento e aumento de sua demanda deve-se constituir no parâmetro básico para análise dessas pretensões de obter "solo criado". O coeficiente de aproveitamento deve ser estabelecido no Plano Diretor, podendo ser único para toda a área urbanizada ou variando por setor de interesse.
A experiência de Porto Alegre foi uma das primeiras na direção de estabelecer índices diferentes para setores das áreas urbanizadas. O "solo criado" corresponde às edificações que ocorram acima do coeficiente estabelecido na Lei Municipal, tanto ocupando o espaço aéreo quanto o subsolo. 0 instrumento permite autorização emitida pelo poder público, para que se possa construir em índices superiores àqueles permitidos. O Plano Diretor deve fixar as áreas nas quais esse instrumento poderá ser operacionalizado mediante contrapartida a ser prestada pelo beneficiário. 0 Estatuto da Cidade define que, por meio da outorga onerosa do direito de construir, o município pode subordinar o exercício individual do direito de construir a uma necessidade social ou ambiental. Por exemplo, a aplicação poderá ocorrer nos casos dos imóveis considerados de interesse ambiental ou destinados à implantação de programas sociais como, por exemplo, programas habitacionais, de regularização fundiária, histórica e cultural.

O Direito de Superfície se funda na compreensão sobre a ampliação do significado da propriedade. Não interessa apenas que se tenha a propriedade da área. Para que haja edificação é necessário que também exista o direito de superfície, obtido pelo registro imobiliário. Trata-se também do direito real para uso por terceiros que poderão edificar em um terreno que não é de sua propriedade. Tal direito real poderá ser temporário ou perpétuo para construir sobre ou sob o terreno ou ainda para praticar o plantio de vegetais. Outro exemplo do direito temporário pode ocorrer em programas de interesse social, vacinação de humanos ou de animas, por exemplo, instalando equipamentos para uso da superfície do solo. Uma possibilidade que se vislumbra é em casos de implantação de determinadas vias públicas, para as quais o poder público utilizará apenas do direito de superfície, sem que se constitua no proprietário do terreno. Outro caso pode ser verificado quando um locatário executa obras de melhoria em um imóvel, com autorização do proprietário, em que tais benefícios poderão representar somente o uso da superfície. Em outras palavras, o Estatuto da Cidade reconhece a existência de um direito que é o de construir, tratado de forma independente de sua relação à propriedade.

0 uso do subsolo e do espaço aéreo tem sido objeto de providências de municípios, cobrando pelas passagens de materiais de companhias energéticas, de telefonia, de saneamento básico e de propaganda. A experiência do município de Rio Claro (SP), ao cobrar o uso do espaço aéreo e sub su- 
perficial por parte das empresas de telefonia e energia eléctrica, resultou em uma demanda judicial que já foi vencida pelo município nas instâncias de recurso. Essa cobrança se dá, tendo em vista que tais serviços são prestados por empresas privadas, muitas vezes detentoras de concessões, cobrando tarifas e taxas de seus clientes e ganhando com o uso dos espaços públicos. Daí, a consideração da exigência de contrapartida financeira para os municípios onde instalam seus equipamentos.

As operações consorciadas têm como objetivo transformar as realidades de áreas urbanas com participação do poder público, da iniciativa privada, dos moradores e proprietários das terras. Na Lei que aprova a aplicação deste instrumento deverá constar a definição da área objeto de transformações, bem como o plano a ser desenvolvido, com previsão dos resultados prognosticados. 0 plano deverá prever as reformas e construções que serão efetuadas, com os devidos índices e caracterização do parcelamento a ser aplicado, para o uso e ocupação do solo. Trata-se de instrumento que deve ser previsto no plano diretor, mas que dependerá das explicitações apontadas. Não há possibilidade da simples aplicação pelo fato de estar previsto no plano diretor, havendo necessidade de aprovação em lei específica, com todos os detalhamentos. As áreas sujeitas à sua aplicação devem constar da Lei, incluindo localização geográfica, identificação por geodesia, propriedades limítrofes, além de apontar seus proprietários e as características físicas dos lotes ou glebas sujeitos à sua aplicação. Portanto não se trata simplesmente de uma carta de intenções.

0 que se tem observado é o especial interesse da indústria da construção civil e promotores imobiliários por este instrumento em específico. De fato, em muitos municípios a aplicação de Operações Consorciadas tem atendido interesses de setores privados, inclusive viabilizando ações anteriormente restritas no escopo da legislação. Foi neste contexto que no município de São Paulo a manifestação dos movimentos sociais explicitou uma posição clara e insofismável ao dizer, nos termos publicados por Raquel Rolnik “Concessão urbanística só serve ao interesse do mercado imobiliário... ao permitir a Concessão Urbanística abriu brechas para as políticas higienistas e para que a ganância do mercado imobiliário avançasse sobre as áreas centrais, expulsando criminalizando as populações de baixa renda e os seguimentos mais vulneráveis, como: população em situação de rua, ambulantes, idosos, da área central da cidade." (R. Rolnik, 2013) Essas afirmações estão claramente consonantes com a visão de Flávio Vila- ça ao abordar o impacto negativo produzido na cidade de São Paulo a partir do uso inadequado do Estatuto da Cidade. Segundo Vilaça, “Em pelo menos um aspecto o Estatuto da Cidade foi um clamoroso retrocesso. Pôs fim ao caráter social e distributivo contido na experiência paulistana das operações interligadas, subordinando-as (agora sob o nome de Operações Urbanas Consorciadas) aos interesses imobiliários. Isso ocorreu ao se introduzir no texto a exigência contida no parágrafo $1^{\circ}$ do item VII do art. 33, que determina que os recursos obtidos através de uma operação "serão aplicados exclusivamente na própria operação urbana consorciada" (Villaça, 2012). Fica explícito que a decisão de atrair investimentos privados traz em seu bojo o interesse desses setores e as populações empobrecidas ficam alijadas do processo. Claro que essa decisão é política e vem carregada de imensa carga ideológica para a defesa da propriedade privada. Demonstra-se assim que a aplicação dos instrumentos do Estatuto da Cidade está subordinada ao atendimento de compromissos assumidos pelos governantes. Está claro que implantar esses instrumentos corresponde aos compromissos com a carga ideológica na qual estão embutidos.

A transferência do direito de construir é outro importante instrumento que perpassa o Estatuto da Cidade. Quando o município efetua o tombamento de uma propriedade, por exemplo, o proprietário poderá pleitear o exercício das normas urbanísticas previstas para esse local, transferindo tais direitos para outro lugar. Esse mesmo instrumento poderá ser aplicado para os casos em que alguma área seja destinada a preservação ambiental ou para operações urbanas de interesse e apontadas no Plano Diretor. O poder público terá que demonstrar a necessária destinação do imóvel, exigindo-se muito cuidado em sua aplicação, considerando-se também os impactos que essas destinações terão para suas vizinhanças. Há circunstâncias em que os benefícios urbanísticos para determinados setores da cidade são de tal monta, que poderão justificar a cobrança de contribuição por melhorias.

Tal como aquele, o Estudo de Impacto de Vizinhança (EIV) também se configura de grande relevância. A exigência de apresentação desse estudo será condição indispensável para a análise em casos de solicitação de licenças e autorização para construção. Quando for o caso e houver exigências legais, tais empreendimentos também estarão sujeitos à apresentação dos Estudos de Impactos Ambientais (EIA) e se desdobrar no Relatório (RIMA). Ou seja, o Estudo de Impacto de Vizinhança não substitui as 
outras exigências que possuem objetivos definidos em leis. Os impactos de vizinhança são relativos, por exemplo, ao aumento da circulação de veículos, demandas de mais áreas para estacionamento e de transportes públicos, impedimento ou dificuldade para a circulação atmosférica e ventilação, exposição ou bloqueio aos raios solares, interceptação de vistas à paisagem, proporcionando valorização ou desvalorização de imóveis. Enfim, muitos são os problemas que poderão decorrer de empreendimentos que precisarão ser conhecidos pelo poder público e pela vizinhança.

O Plano Diretor de Tupaciguara considera a necessidade de elaboração de Estudo de Impacto de Vizinhança na seção II do capítulo VII, Art. 149 a 155. Destaca-se que o Município exigirá dos empreendimentos e atividades, considerados impactantes sobre a cidade, conforme artigos 36 a 38 do Estatuto da Cidade, a elaboração de estudo prévio de impacto de vizinhança - EIV para a concessão das licenças e autorizações de funcionamento. Considera-se que estes empreendimentos correspondem àqueles que tenham usos ou atividades, públicas ou privadas, residenciais ou não residenciais que possam causar impacto ou alteração no ambiente natural ou construído ou provocar sobrecarga na capacidade de atendimento de infra-estrutura básica. O Art. 155 lembra que a elaboração do estudo de impacto de vizinhança e seu respectivo relatório não é substituído pelos demais documentos que são exigidos, quando for o caso. Porém, não é conhecido o fato de que a Prefeitura de Tupaciguara tenha tido a iniciativa de exigir de algum empreendimento a elaboração de EIV.

Decorridos mais de dez anos da promulgação do Estatuto da Cidade e contando com Planos Diretores já formulados à luz destes instrumentos, após a consideração dos mesmos para a reflexão aqui exposta, podemos fazer algumas considerações. Se a experiência democrática traz em si a exigência da permanente reflexão sobre o fazer com vistas à sua reelaboração em condição superior, os Planos Diretores de Uberlândia e Tupaciguara já apresentam elementos que merecem ser revistos. De fato, o fazer democrático e participativo hoje constitui e se apresenta em condições que se é possível também apontar como não fazer, além de apontar algumas boas experiências. Na última década, estes municípios, especialmente Uberlândia, mas também Tupaciguara foram dinamizadas pelo próprio processo de reprodução social do espaço. Contudo, em ambos, viu-se a recorrência a práticas conservadoras como a produção de conjuntos habitacionais nos limites do perímetro urbano.

Entretanto, pela natureza progressista de novas práticas possíveis do Estatuto da Cidade, chama muito a atenção o fato de nos dois municípios importantes instrumentos possíveis do Estatuto da $\mathrm{Ci}$ dade e respaldados nos respectivos Planos Diretores, não terem sido adotados de forma sistemática. IPTU progressivo, Exigência do EIV, Outorga Onerosa, Usucapião Urbano, entre outros, embora sejam práticas legalmente respaldadas, demandadas nos dois municípios, não se configuram como instrumentos efetivos para o fazer cumprir da função social da propriedade em prol dos interesses sociais coletivos.

Desta maneira, talvez tão importante quanto as mudanças trazidas pelos planos diretores na consideração destes à luz do Estatuto da Cidade, sejam suas ausências ou suas não aplicações. Isto porque, a não aplicação dos instrumentos mais progressistas joga luz ao fato de que o campo de disputa em torno da cidade que queremos não se restringe à luta do Processo Instituinte. Como também não se satisfaz pela regulamentação na forma do Estatuto da Cidade ou mesmo de sua materialização nos respectivos planos diretores. 0 que se revela é que o instituído, mesmo quando regulamentado, só é transformador em seu exercício efetivo. Explicita-se então, a necessidade constante, sistemática e rigorosa, da efetiva participação da população na produção da cidade. Entretanto, se o que norteia é a cidadania e esta se compõe de deveres e direitos, talvez resida aí um importante componente da cidade e da sociedade que queremos.

\section{Bibliografia}

Damiani, Amélia Luísa (2000). A metrópole e a indústria: reflexões sobre uma urbanização crítica. Revista Terra Livre. Número 15, 21-38.

Morin, Edgar (1994). Introducción al pensamiento complejo. Barcelona. Gedisa.

CEPAM - Fundação Prefeito Faria Lima (2001). Estatuto da Cidade, coordenação por Mariana Moreira. São Paulo.

Galeano, Eduardo (1988). La ciudad. La canción de nosotros. Imprensa Rosgal S.A. Montevideo.

Harvey, David (2005). A Produção Capitalista do Espaço. São Paulo: Editora Annablume.

Lefebvre, Henri (1999). O Direito à Cidade. Belo Horizonte: Editora UFMG.

Montoro, André Franco. Introdução à Ciência do Direito. 31 ed. São Paulo: Revista dos Tribunais. 
Oliveira, Francisco (2003). Crítica à Razão Dualista e o Ornitorrinco. São Paulo: Boitempo Editorial.

Oliveira, Isabel Cristina Eiras (2001). Estatuto da Cidade: para compreender. Rio de Janeiro. IBAM/DUMA.

Planos Diretores Municipais: integração regional estratégica - roteiro metodológico. Coordenador Carlos Geraldo Luz de Freitas. Porto Alegre. ANTAC.2007. Coleção Habitare, 7.

Plano Diretor Participativo: Guia para Elaboração pelos Municípios e Cidadãos. Produção do Ministério das Cidades e CONFEA - maio-junho de 2004.

Plano Diretor do Município de Tupaciguara - lei complementar $\mathrm{N}^{\circ} 96 / 2007$

Plano Diretor do Município de Uberlândia

Corrêa, Roberto Lobato (1995). O Espaço Urbano. Editora Ática, Série Princípios, 3a. edição, n. 174, 1-16.2.
Rolnik, Raquel (2013). Manifesto das Entidades Populares e Movimentos de Moradia sobre o Plano Diretor. Blog da Raquel Rolnik publicado em 10/09/2013, acesso pelo link

http: / / raquelrolnik.wordpress.com/2013/09/10/manifestodas-entidades-populares-e-movimentos-de-moradiasobre-o-plano-diretor/

Santos, Milton (1994). Técnica, espaço e tempo. São Paulo. HUCITEC.

Villaça, Flávio (2012). Estatuto da Cidade: Para que Serve? Carta Capital,19 de outubro de 2012. Acesso em 16 de setembro de 2013-09-16

http://www.cartamaior.com.br/templates/materiaMostrar. cfm?materia_id $=21113$ 